\title{
Macular Degeneration: Case-Report of a Peculiar Sunlight Exposure in an Agricultural Worker
}

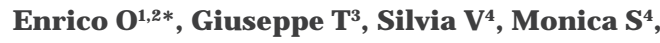 \\ Francesco $\mathrm{F}^{2}$ and Marcello $\mathrm{I}^{1,2}$ \\ ${ }^{1}$ Department of Public Health, Experimental and Forensic \\ Medicine, Occupational Medicine Unit "Salvatore \\ Maugeri", University of Pavia, Italy \\ ${ }^{2}$ Department of Occupational Medicine, Toxicology \\ and Environmental Risks, IRCCS "Salvatore Maugeri" \\ Foundation, Italy \\ ${ }^{3}$ Department of Occupational Medicine, Toxicology and \\ Environmental Risks, Hospital Occupational Medicine \\ Unit (UOOML), IRCCS “Salvatore Maugeri” Foundation, \\ Italy \\ ${ }^{4}$ Ophthalmologic Rehabilitation Unit, IRCCS “Salvatore \\ Maugeri" Foundation, Italy \\ *Corresponding author: Enrico O, Department of \\ Public Health, Experimental and Forensic Medicine, \\ Occupational Medicine Unit "Salvatore Maugeri", \\ University of Pavia, Pavia, Italy
}

Received: December 05, 2016; Accepted: February 16, 2017; Published: February 22, 2017

\section{Introduction}

Sunlight is currently considered as a suspected risk factor for Age-related Macular Degeneration (AMD), in particular for those patients who have had prolonged exposures during their working life [1]. Starting from the ' 90 s, several studies pointed out interesting results, ranging from slight not significant increase in risk to two or even four-fold increased risks, as reported by a recent meta-analysis which underlined a pooled Odds Ratio (OR) of AMD (OR 1.38, 95\% CI 1.09-1.74, $\mathrm{p}=0.007$ ) for people exposed to sunlight [2].

These observations are of particular interest for the occupational medicine, due to the wide variety of employments in which the sunlight exposure is frequent: farmers, gardeners, fishermen, watermen, mountain guides are all examples of occupations in which such a kind of risk could not be disregarded, although the circumstances of exposure could be very different from a task to another. Furthermore, welders $[3,4]$ and other indoor workers $[5,6]$ can be considered at risk for AMD, as deepened in the following, especially due to exposure to the portion of the visible light spectrum ranging from 380 to $550 \mathrm{~nm}$ of wavelength.

The aim of this report is to highlight the case of women former employed in agriculture in such a particular task, who later developed an AMD, and to depict the risk related also to short but intense sunlight exposures, without using any personal protective equipment.

\section{Case Description}

A bilateral dry AMD was diagnosed in 2008 to a woman of 75 years of age. She currently suffers from hypertension, hyperthyroidism and rheumatoid arthritis, for which a therapy with ramipril, methimazole and lorazepam was set up. She had a surgical intervention at the age of
62 for a breast cancer, and in 2006 she underwent a surgical treatment for cataract to both the eyes. No family history for AMD was detected, nor for diabetes, hypertension and autoimmune diseases. She did not report any use of chloroquine or similar compounds in the past, while a smoking habit was reported between about 30 and 50 years of age (10 cigarettes per day). No detailed information was available regarding her diet, nor regarding the antioxidants assumptions.

At the most recent Optical Coherent Tomography (OCT), carried out in May 2016, several drusenoid detachments of the retinal pigment epithelium (PED) were observed in the right eye, and confluence of drusen in the left eye.

Starting from 1948, at the age of 15 years, she worked as a farmer for about 8 years, and during the further 2 years she was employed as "mondina". This was a particular task consisting in the transplantation of little rice plants into water-flooded fields and in the manual cleaning of the plantations from the infesting grasses. In fact, the Italian term "mondina", or its synonym "mondariso", originates from the verb "mondare", i.e. to clean. Nowadays, in western countries, this occupation has disappeared, replaced by pesticides, although it has been a frequent female occupation during the XIX century and the first half of the XX century, mostly in the Italian North-West plains, where Pavia is located. No personal protective equipment was provided to these female workers, except a brimmed hat useful to protect the head for the sun, but probably not to protect the eyes from the sun reflection on the water. This exposure, together with prolonged forced postures, contributed to make this occupation particularly unhealthy, so much to become a social issue and to inspire "Risoamaro" (bitter rice), film Oscar nominated in 1951.

No further occupational exposures were reported, except 3 years
Austin J Public Health Epidemiol - Volume 4 Issue 1 - 2017 ISSN : 2381-9014 | www.austinpublishing group.com Enrico et al. (C) All rights are reserved
Citation: Enrico O, Giuseppe T, Silvia V, Monica S, Francesco F and Marcello I. Macular Degeneration: CaseReport of a Peculiar Sunlight Exposure in an Agricultural Worker. Austin J Public Health Epidemiol. 2017; 4(1): 1055. 
as labourer in a chemical plant devoted to the production of synthetic textiles (rayon fibres).

\section{Discussion}

Despite its protective action in several pathologies, sunlight exposure is a known risk factor for some diseases. Evidence is present that point out a causal role of sunlight exposure in the onset of AMD $[1,2]$. In particular, exposure to blue light (i. e. the portion of the spectrum of visible light in a wavelength range between 380 and $550 \mathrm{~nm}$ ) causes retinal damage and is considered to be responsible for frameworks of AMD. Experimental data are available and show retinal damages induced by blue light $[7,8]$. Although the pathogenic mechanism of AMD is not thus far completely understood, it seems clear that blue-light exposure can induce oxidative stress in the retina $[1,7]$ : animal experiment showed that some retinal chromophores, like A2E, can induce a phototoxic damage when oxidized by bluelight [9]. Moreover, it was observed that blue-light photoreactivity of melanosomes intensifies with aging [10], providing, along with the aerobic photoreactivity of retinal pigment epithelium lipofuscin [11], other potential sources of reactive oxygen species, and thus contributing to cellular dysfunction.

Several epidemiologic studies suggest a correlation between sunlight exposure and the development of AMD. Some of them showed remarkable and significant increase in risks [12-14], while a recent meta-analysis indicates a pooled risk estimation of about 1.38 (95\% CI 1.09-1.74) [2]. It has to be noticed that two of these studies were carried out on the population of islands located in the Adriatic sea (Croatia) [12,14], in which a large part of the residents is occupied as fishermen or agriculturists, according the definition of the authors [14]. These results are consistent with previous one, underlining increased risks for watermen exposed to blue-light [15]. Despite the difference existing between fishermen or watermen and "mondine", their occupational tasks are associated by the exposure to the sunlight reflection on the water surface in addition to directly natural light exposure.

Some indoor exposures were observed to be related to AMD. In particular, occupational welders using welding arc showed increased risks for macular degeneration, $[3,4,16]$ and exposure to blue-light of medical personnel in dentistry [5] or dermatology[6] is raising increasing concern.

Exposure to sunlight during the teenage years and thirties was found to be related with early AMD $[1,17,18]$. Although our case has had no such an early onset, it is interesting to notice that she had an early exposure started at 15 and ended at 25 years of age, with the latter two years accounting for the most intense exposure to sunlight. Conversely to the short time of exposure, the time since first exposure has a remarkable length, being approximately of 60 years.

Despite the rarity of this exposure and the out datedness of the task, this case has the advantage to highlight how sunlight exposure could exert its damaging action on the retina also for short duration of exposure and with a considerably latency time. According to the literature evidence, blue-light is probably the most dangerous part of the visible light for macular degeneration $[7,8]$. This consideration demands to pay attention also to those exposures to artificial light which have the same wavelength of blue-light, and in particular to assess risks in all occupational settings in which workers use bluelight emitting devices.

Finally, we are aware that our case holds several other risk factors for AMD, such as hypertension and smoking habits, along with a complicated clinical history, though we think that this case suggests an interaction between environmental/occupational risks factors and personal behaviors, pointing out the need of paying particular attention to the additive occupational risk burden in such a wide productive sector like agriculture.

\section{Conclusion}

In conclusion, we think that this brief case-report could highlight those occupational exposures to sunlight, and especially to the short wavelength component of its spectrum, deserve further attention to set preventive measures and to adopt the adequate personal protective equipments, in order to prevent the onset of AMD.

\section{References}

1. Schick T, Ersoy L, Lechanteur YT, Saksens NT, Hoyng CB, Den Hollander $\mathrm{Al}$, et al. History of sunlight exposure is a risk factor for age-related macular degeneration. Retina. 2016; 36: 787-790.

2. Sui GY, Liu GC, Liu GY, Gao YY, Deng Y, Wang WY, et al. Is sunlight exposure a risk factor for age-related macular degeneration? A systematic review and meta-analysis. Br J Ophthalmol. 2013; 97: 389-394.

3. Yang X, Shao D, Ding X, Liang X, Yang J, Li J. Chronic phototoxic maculopathy caused by welding arc in occupational welders. Can J Ophthalmol. 2012; 47: 45-50.

4. Vukicevic M, Heriot W. Phototoxic maculopathy associated with arc welding: clinical findings and associated functional vision impairment. Clin Experiment Ophthalmol. 2008; 36: 695-697.

5. Price RB, Labrie D, Bruzell EM, Sliney DH, Strassler HE. The Dental Curing Light: A Potential Health Risk. J Occup Environ Hyg. 2016; 13: 639-646.

6. Walker DP, Vollmer-Snarr HR, Eberting CL. Ocular hazards of blue-light therapy in dermatology. J Am Acad Dermatol. 2012; 66: 130-135.

7. Algvere PV, Marshall J, Seregard S. Age-related maculopathy and the impact of blue light hazard. Acta Ophthalmol Scand. 2006; 84: 4-15.

8. Pang J, Seko Y, Tokoro T, Ichinose S, Yamamoto H. Observation of ultrastructural changes in cultured retinal pigment epithelium following exposure to blue light. Graefes Arch Clin Exp Ophthalmol. 1998; 236: 696701.

9. Wielgus AR, Collier RJ, Martin E, Lih FB, Tomer KB, Chignell CF, et al. Blue light induced $\mathrm{A} 2 \mathrm{E}$ oxidation in rat eyes--experimental animal model of dry AMD. Photochem Photobiol Sci. 2010; 9: 1505-1512.

10. Rozanowska M, Pawlak A, Rozanowski B, Skumatz C, Zareba M, Boulton $\mathrm{ME}$, et al. Age-related changes in the photoreactivity of retinal lipofuscin granules: role of chloroform-insoluble components. Invest Ophthalmol Vis Sci. 2004; 45: 1052-1060.

11. Rozanowska M, Korytowski W, Rozanowski B, Skumatz C, Boulton ME Burke JM, et al. Photoreactivity of aged human RPE melanosomes: a comparison with lipofuscin. Invest Ophthalmol Vis Sci. 2002; 43: 2088-2096.

12. Plestina-Borjan I, Klinger-Lasic M. Long-term exposure to solar ultraviolet radiation as a risk factor for age-related macular degeneration. Coll Antropol. 2007; 31: 33-38.

13. Hirakawa M, Tanaka M, Tanaka Y, Okubo A, Koriyama C, Tsuji M, et al. Age-related maculopathy and sunlight exposure evaluated by objective measurement. Br J Ophthalmol. 2008; 92: 630-634.

14. Vojniković B, Njirić S, Coklo M, Spanjol J. Ultraviolet sun radiation and incidence of age-related macular degeneration on Croatian Island Rab. Coll Antropol. 2007; 31: 43-44. 
15. Taylor HR, West S, Munoz B, Rosenthal FS, Bressler SB, Bressler NM. The long-term effects of visible light on the eye. Arch Ophthalmol. 1992; 110: 99104

16. Li Q, Zhang X. [The Influence of risk factors on visual performance in of phototoxic maculopathy in occupational welders]. Zhonghua lao dong wei sheng zhi ye bing za zhi (Chinese journal of industrial hygiene and occupational diseases). 2014; 32: 759-761. Chinese.
17. Cruickshanks KJ, Klein R, Klein BE. Sunlight and age-related macular degeneration. The Beaver Dam Eye Study. Arch Ophthalmol. 1993; 111 514-518.

18. Klein BE, Howard KP, lyengar SK, Sivakumaran TA, Meyers KJ, Cruickshanks $\mathrm{KJ}$, et al. Sunlight exposure, pigmentation, and incident age-related macular degeneration. Invest Ophthalmol Vis Sci. 2014; 55: 5855-5861.
Austin J Public Health Epidemiol - Volume 4 Issue 1 - 2017

ISSN : 2381-9014 | www.austinpublishing group.com

Enrico et al. (C) All rights are reserved
Citation: Enrico O, Giuseppe T, Silvia V, Monica S, Francesco F and Marcello I. Macular Degeneration: CaseReport of a Peculiar Sunlight Exposure in an Agricultural Worker. Austin J Public Health Epidemiol. 2017; 4(1): 1055. 